\title{
Cerebroventricular Calcitonin Gene-related Peptide Inhibits Rat Duodenal Bicarbonate Secretion by Release of Norepinephrine and Vasopressin
}

\author{
H. Jürgen Lenz and Marvin R. Brown \\ Neurogastroenterology Laboratory, Department of Medicine, University of Hamburg, Hamburg, Federal Republic of Germany; and \\ Autonomic Physiology Laboratory, Departments of Medicine and Surgery, University of California, San Diego, California 92103
}

\begin{abstract}
Proximal duodenal bicarbonate secretion is an important factor in humans and animals protecting the mucosa against acidpeptic damage. This study examined the mechanisms responsible for the central nervous system regulation of duodenal bicarbonate secretion by calcitonin gene-related peptide (CGRP) in unrestrained rats. Cerebroventricular administration of rat CGRP significantly inhibited basal duodenal bicarbonate secretion as well as the stimulatory effects of vasoactive intestinal peptide, neurotensin, a luminal PGE 1 analogue, misoprostol, and hydrochloric acid. The inhibitory effects of cerebroventricular CGRP were abolished by ganglionic blockade with chlorisondamine, significantly attenuated by noradrenergic blockade with bretylium, and enhanced by vagotomy. Inhibition of duodenal bicarbonate secretion induced by CGRP coincided with significant increases in plasma norepinephrine (NE) and vasopressin concentrations. The alpha adrenergic receptor antagonist, phentolamine, and the vasopressin $V_{1}$ receptor antagonist, (1-deaminopenicillamine, 2-[O-methyl]Tyr, 8-Arg)-vasopressin, given intravenously reversed the central inhibitory effect of CGRP by 50\% each. Pretreatment of the animals with both phentolamine and the vasopressin antagonist completely abolished the central inhibitory effect of CGRP. Peripheral vasopressin and NE significantly decreased duodenal bicarbonate secretion, and their inhibitory effects were additive and prevented by phentolamine and the vasopressin antagonist, respectively. We conclude that cerebroventricular CGRP inhibits rat duodenal bicarbonate secretion by activation of sympathetic efferents and subsequent release of $\mathrm{NE}$ and vasopressin that act on alpha adrenergic and vasopressin receptors, respectively. (J. Clin. Invest. 1990. 85:2532.) autonomic nervous system - brain-gut axis - calcitonin gene-related peptide $\bullet$ duodenal bicarbonate secretion $\bullet$ neuropeptides • vasopressin
\end{abstract}

\section{Introduction}

Duodenal bicarbonate secretion protects the mucosa against acid-peptic damage in humans and animals (1-4). Diminished proximal duodenal bicarbonate secretion at rest and in response to hydrochloric acid appears to be an important factor in the pathogenesis of duodenal ulcer disease (5). Like most

Address correspondence to Dr. H. Jürgen Lenz, Division of Gastroenterology, Department of Medicine, UCSD Medical Center (H 811 D), 225 Dickinson Street, San Diego, CA 92103.

Received for publication 22 February 1989 and in revised form 2 August 1989.

J. Clin. Invest.

(c) The American Society for Clinical Investigation, Inc.

0021-9738/90/01/0025/08 $\$ 2.00$

Volume 85, January 1990, 25-32 gut secretory processes, duodenal bicarbonate secretion is controlled by the autonomic nervous system. Stimulation of parasympathetic (vagal) efferents increases while stimulation of sympathetic (splanchnic) efferents decreases duodenal bicarbonate secretion $(6,7)$. Corticotropin-releasing factor is an endogenous central nervous system transmitter that mediates stimulation of duodenal bicarbonate secretion during stress by release of $\beta$-endorphin from the pituitary (8). Thyrotropin-releasing hormone is a candidate central nervous system transmitter that stimulates gastric acid and duodenal bicarbonate secretion by increasing vagal outflow (9). The central nervous system transmitter(s) that mediates inhibition of duodenal bicarbonate secretion in situations of increased noradrenergic activity is unknown.

We have recently screened 10 neuropeptides and tested their central nervous system effects on proximal duodenal bicarbonate secretion in awake, nonrestrained rats (10). Calcitonin gene-related peptide (CGRP; 11$)^{1}$ was the only peptide that significantly inhibited proximal duodenal bicarbonate secretion (10). This peptide selectively stimulates noradrenergic sympathetic outflow (12) and potently inhibits gastric acid secretion and gastrointestinal transit in rats and dogs (13-19). The purposes of the present investigation were threefold: $(a)$ to examine the pharmacological properties of CGRP to inhibit resting and stimulated duodenal bicarbonate secretion in awake, freely moving rats; $(b)$ to determine the pathways that are involved in mediating the central nervous system effects of CGRP; and (c) to study the peripheral effects of presumed transmitters released by CGRP. Our results indicate that cerebroventricular CGRP inhibits resting and stimulated duodenal bicarbonate secretion by stimulation of noradrenergic sympathetic outflow and vasopressin release. They also demonstrate that the inhibitory effects of peripheral NE and vasopressin on bicarbonate secretion are synergistic and mediated by specific alpha adrenergic and vasopressin receptors.

\section{Methods}

Male Sprague-Dawley rats $(250-300 \mathrm{~g})$ were used. The animals were housed in separate cages under illumination-, temperature-, and humidity-controlled conditions, and fed a standard rat diet before and a liquid diet after surgery. 4 to $7 \mathrm{~d}$ before the first experiment the proximal duodenum was isolated under general anesthesia (ketamine-HCl, $50 \mathrm{mg} / \mathrm{kg}$; Ketanest [Parke Davis \& Co., Berlin, FRG]; and xylazine, 6 $\mathrm{mg} / \mathrm{kg}$ [Rompun, Bayer AG, Leverkusen, FRG]). Paying particular attention to the integrity of surrounding pancreatic tissue and blood supply, the first $2 \mathrm{~cm}$ of the duodenum (proximal to the pancreatic duct) were isolated and the pylorus anastomosed to the distal duodenum by seven to eight single sutures. The proximal and distal ends of the isolated duodenal segment were connected with polyethylene catheters (PE-90) and secured by purse string sutures. The catheters then were routed subcutaneously to exit in the interscapular region of

1. Abbreviations used in this paper: CGRP, calcitonin gene-related peptide; VIP, vasoactive intestinal peptide. 
the animal's neck. They were closed with cut needle ends that served as connectors for catheters used to perfuse the duodenal segment and to collect duodenal perfusates. After surgery the segment was flushed every $8 \mathrm{~h}$ with $5 \mathrm{ml}$ of $0.15 \mathrm{M} \mathrm{NaCl}$ to remove duodenal mucus and maintain patency of the segment and catheters (8).

During a second surgery (2-4 $d$ before the experiment and 3-5 $d$ after the intestinal surgery), a 22-gauge stainless steel cannula (Plastic Products Co., Roanoke, VA) was implanted using a stereotaxic instrument (David Kopf Instruments, Tujunga, CA) so that its tip was inside the right cerebral ventricle (20). In each animal, correct cannula placement was verified by injection of methylene blue (20). The animals were also fitted with a right jugular venous catheter (PE-50) that was routed subcutaneously to exit in the interscapular region of the animal's neck, where it was closed by a cut needle end and secured with adhesive tape (20). In some animals, bilateral, truncal, subdiaphragmatic vagotomy, or adrenalectomy were performed as previously described (20). Hypophysectomized animals were commercially obtained (Wiga, Sülzfeld, FRG). Completeness of adrenalectomy and hypophysectomy were documented by macroscopic inspection. To demonstrate completeness of vagotomy, a 2-deoxy-D-glucose test (100 $\mathrm{mg} / \mathrm{kg} \cdot 3 \mathrm{~min}$; Sigma Chemie GmbH, Deisenhofen, FRG) was performed (20). Adrenalectomized and hypophysectomized animals had free access to $0.15 \mathrm{M} \mathrm{NaCl}$.

On the day of the experiment the animals were placed into 15 -liter buckets to which they were accustomed. They were fasted for $16 \mathrm{~h}$ but had free access to tap water until the beginning of the experiment. The cerebroventricular cannula was connected with a polyethylene catheter (PE-10), the jugular vein catheter with PE-50, and the duodenal catheters with PE-90. The duodenal segment was constantly perfused with $0.15 \mathrm{M} \mathrm{NaCl}\left(39^{\circ} \mathrm{C}, 30 \mathrm{ml} / \mathrm{h}\right)$ and the effluent collected at $15-\mathrm{min}$ intervals in graduated cone vials. To clear the segment from residual mucus and secretions, the first four collections were discarded (8). Rat CGRP and calcitonin (16) were injected cerebroventricularly or intravenously over $1 \mathrm{~min}$ in $10-\mu \mathrm{l}$ and $0.5-\mathrm{ml}$ volumes, respectively (16). Peptides were kindly provided by Dr. Jean E. Rivier (Salk Institute, La Jolla, CA), stored in lyophylized form, and freshly dissolved in sterile water before each experiment. The vehicle, sterile water, served as control.

Bicarbonate concentrations of the duodenal effluent were measured by a validated back-titration method for low bicarbonate concentrations $(2,8)$. Measurements were performed in triplicate. A 2-ml aliquot of the effluent was added to $5 \mathrm{ml}$ of $\mathrm{CO}_{2}$-free $\mathrm{H}_{2} \mathrm{O}$ and acidified with $125 \mu \mathrm{l}$ of $100 \mathrm{mM} \mathrm{H}_{2} \mathrm{SO}_{4}$. To remove any residual $\mathrm{CO}_{2}$, the solution was gassed for $5 \mathrm{~min}$ with $\mathrm{N}_{2}$ and washed with $\mathrm{Ba}(\mathrm{OH})_{2}$. The sample then was titrated by the addition of $15 \mathrm{mM} \mathrm{NaOH}$ under continuous gassing with $\mathrm{N}_{2}$ to $\mathrm{pH} 8.4$ on an automated titration system (Autoburette ABU SO, Titrator TTT 80, pH meter PHM 82; Radiometer, Copenhagen, Denmark). On each test day the perfusates that served as blank and bicarbonate standards $(0.65,1.3$, and $2.6 \mathrm{mM})$ were measured to assure reproducibility (8).

To ascertain that CGRP did not increase mucosal permeability, recovery studies with exogenous bicarbonate were performed. The duodenal segment was perfused with $22 \mathrm{mM} \mathrm{HCO}_{3}^{-}(30 \mathrm{ml} / \mathrm{h})$ for $2 \mathrm{~h}$ $(1,320 \mu \mathrm{mol} / 2 \mathrm{~h})$. CGRP $(1 \mathrm{nmol})$ or control (sterile water) were given cerebroventricularly at the zero time point. The mean $( \pm$ SE) bicarbonate outputs in control and CGRP-treated animals $(n=8)$ were $1,364 \pm 14$ and $1,331 \pm 16 \mu \mathrm{mol} / 2 \mathrm{~h}$, respectively, and were not signifcantly different from one another. The amount of recovered bicarbonate that was greater than the amount of exogenously infused bicarbonate reflects active bicarbonate secretion in the presence and absence of central CGRP.

In dose-response studies the cerebroventricular effects of CGRP were tested on basal (resting) and stimulated duodenal bicarbonate secretion. Each dose $(0,0.01,0.1$, and $1 \mathrm{nmol} /$ animal) was administered on a separate day and in random order. Bicarbonate secretion after intravenous injection of $0.15 \mathrm{M} \mathrm{NaCl}(0.5 \mathrm{ml})$ served as control. Stimulated bicarbonate secretion was measured in response to intravenous bolus injection of neurotensin or vasoactive intestinal peptide
(VIP; $10 \mathrm{nmol} / \mathrm{kg}$ each) and in response to a 5-min duodenal perfusion with $0.15 \mathrm{M} \mathrm{HCl}$ or during continuous perfusion of the duodenal segment with a $P G E_{1}$ analogue, $( \pm)$ methyl(11 $\left.\alpha, 13 E\right)$-11,16-dihydroxy-16-methyl-9-oxoprost-13-en-1-oate (misoprostol, 10-5 M; G. D. Searle, Skokie, IL). CGRP was given at the same time the intravenous or duodenal substances were administered. Pilot studies indicated that the greatest bicarbonate responses occurred between 30 and $45 \mathrm{~min}$ after injection of the intravenous or intraduodenal stimulants. This interval was used for dose-response studies.

To delineate the pathways that may be involved in mediating the central nervous system effects of CGRP on duodenal bicarbonate secretion, pharmacological approaches were used in addition to surgical vagotomy, adrenalectomy, and hypophysectomy. To determine the role of peripheral vasopressin, the $V_{1}$ vasopressin receptor antagonist, (1-deaminopenicillamine, 2-[0-methyl]tyrosine, 8-arginine)-vasopres$\sin (100 \mathrm{nmol} / \mathrm{kg} \cdot \mathrm{h})$, was used (21). This antagonist was provided by Dr. Jean E. Rivier (Salk Institute). Alpha adrenergic receptor blockade was performed with phentolamine $(1 \mu \mathrm{mol} / \mathrm{kg} \cdot \mathrm{h}$; Regitin, Ciba-Geigy $\mathrm{GmbH}$, Wehr, FRG). Preventing the release of NE from noradrenergic nerve endings was achieved with bretylium tosylate $(25 \mathrm{mg} / \mathrm{kg} \cdot \mathrm{h}$; Bretylol, American Critical Care, American Hospital Supply Corp., McGaw Park, IL) (17). Ganglion blockade of autonomic efferents was performed with chlorisondamine $(3 \mathrm{mg} / \mathrm{kg} \cdot \mathrm{h}$; Ecolid, Ciba-Geigy, Basal, Switzerland) (20). Opiate receptor blockade was achieved with naloxone $(1 \mathrm{mg} / \mathrm{kg} \cdot \mathrm{h}$; Sigma Chemie GmbH) (8). Intravenous infusion of these agents was begun $1 \mathrm{~h}$ before bicarbonate measurements and $2 \mathrm{~h}$ before cerebroventricular injection of CGRP. Except for alpha adrenergic blockade with phentolamine, these pharmacological approaches were previously validated $(8,9,15,17,19,20)$. The effectiveness of phentolamine in blocking the actions of NE on duodenal bicarbonate secretion was documented in this study.

Dose-response studies were performed with NE $(5,25$, and 50 $\mathrm{nmol} / \mathrm{kg}$; Arterenol, Hoechst AG, Frankfurt, FRG) and (8-arginine)vasopressin $(0.05,0.25$, and $0.5 \mathrm{nmol} / \mathrm{kg}$; provided by Dr. Jean $\mathrm{E}$. Rivier). Each dose was given intreperitoneally on a separate day and in random order and the 30-45-min interval after injection (interval of greatest response) was used for analysis. In some experiments NE and vasopressin were given concomitantly. In other experiments phentolamine or the vasopressin antagonist were given intravenously as constant infusions before intraperitoneal administration of $\mathrm{NE}$ or vasopressin.

Venous blood was aspirated at times 0,15 , and $30 \mathrm{~min}$ for determination of plasma concentrations of epinephrine and NE $(0.6 \mathrm{ml} / \mathrm{sam}$ ple) and vasopressin (1.2 ml/sample) in separate groups of animals. In additional experiments vasopressin $(0.5 \mathrm{nmol} / \mathrm{kg})$ and $\mathrm{NE}(50 \mathrm{nmol} /$ $\mathrm{kg}$ ) were injected intraperitoneally and plasma concentrations of vasopressin and NE were determined before and $30 \mathrm{~min}$ after injection. Blood was replaced by equal volumes of $0.15 \mathrm{M} \mathrm{NaCl}$. Blood was collected in chilled tubes, centrifuged at $3,000 \mathrm{~g}\left(4^{\circ} \mathrm{C}\right)$, and stored at $-20^{\circ} \mathrm{C}$. Plasma catecholamine concentrations were determined by a single isotope radioenzymatic method (22). $s$-[methyl $\left.{ }^{3} \mathrm{H}\right]$ Adenosyl-Lmethionine was purchased from New England Nuclear (Boston, MA). Plasma vasopressin concentrations were determined by RIA using the antiserum kindly provided by Dr. John D. Fernstrom (University of Pittsburgh, Pittsburgh, PA) (23). Plasma was extracted as previously described (24). The minimal detection of this assay was $250 \mathrm{pg} /$ tube and the intraassay variation was $3 \%$. Catecholamine and vasopressin measurements were performed in duplicate and in single assays.

The data were subjected to analysis of variance and differences between treatment groups were determined by the Neuman-Keuls multiple range test (25). Results obtained from six to eight animals in each group were expressed as means $( \pm \mathrm{SE})$ and considered significant if $P<0.05$.

\section{Results}

Intravenous bolus injection of neurotensin and VIP, as well as 5-min duodenal perfusion with the PG $\mathrm{E}_{1}$ analogue, miso- 


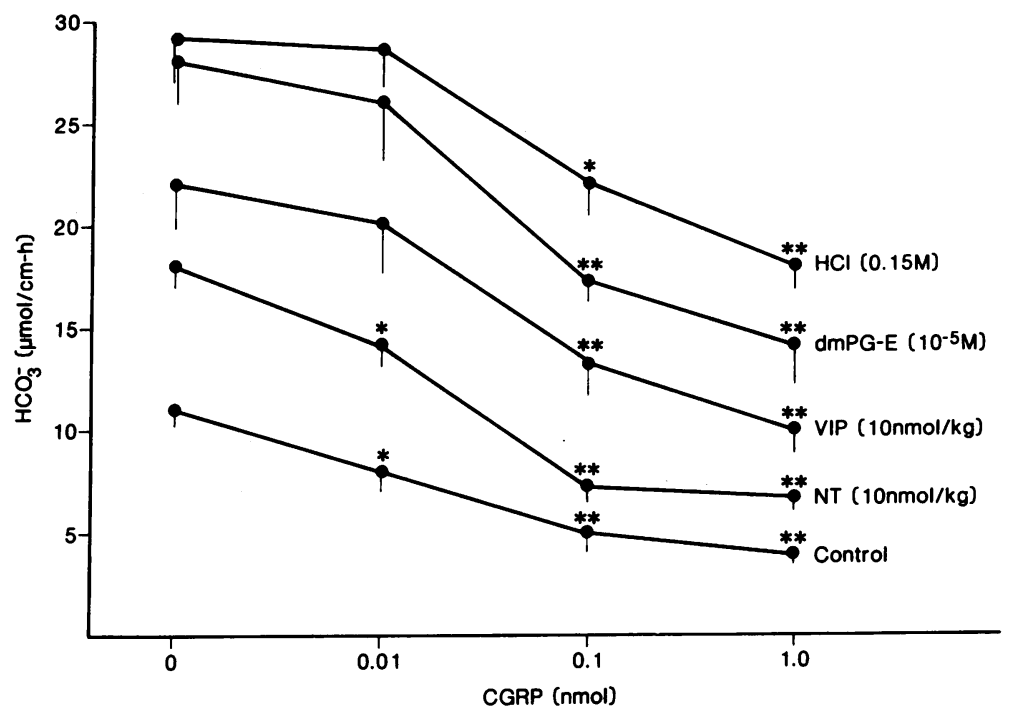

Figure 1. Central nervous system effects of CGRP on proximal duodenal bicarbonate secretion in freely moving rats. $\mathrm{HCl}$ was given intraduodenally for $5 \mathrm{~min}$, a synthetic $P G \mathrm{E}_{1}$ analogue, misoprostol $(d m P G-E)$, was given intraduodenally as a constant infusion, and VIP, neurotensin $(N T)$, and control $(0.15 \mathrm{M} \mathrm{NaCl})$ were given intravenously. CGRP or the vehicle (zero dose) were given cerebroventricularly at the time intraduodenal or intravenous stimuli were administered. The bicarbonate response was measured during the 30-45-min interval (interval of maximal response) after cerebroventricular injection. Doses of CGRP were given in random order and on separate days. ${ }^{*} P<0.05 ;{ }^{* *} P<0.01$ compared with the zero dose. prostol, and $0.15 \mathrm{M} \mathrm{HCl}$ significantly $(P<0.01)$ increased proximal duodenal bicarbonate secretion in control experiments (zero dose CGRP, Fig. 1). At the doses tested the luminal agents (misoprostol and $\mathrm{HCl}$ ) were significantly $(P$ $<0.01$ ) more effective than the two gastrointestinal peptides (neurotensin and VIP). Increasing doses of CGRP given cerebroventricularly resulted in significant and dose-dependent inhibition of basal (resting) and stimulated bicarbonate secretion (Fig. 1). In contrast, cerebroventricular administration of rat calcitonin $(1 \mathrm{nmol})$ did not significantly alter duodenal bicarbonate secretion $(11.5 \pm 0.7 \mu \mathrm{mol} / \mathrm{cm} \cdot \mathrm{h}$ in control experiments and $10.9+0.9 \mu \mathrm{mol} / \mathrm{cm} \cdot \mathrm{h}$ in animals treated with calcitonin [measured during the 30-45-min interval after cerebroventricular injection]; $n=6$ in each group).

Intravenous bolus injection of CGRP ( $1 \mathrm{nmol})$ resulted in an early and transient decrease in duodenal bicarbonate secretion $(P<0.01)$, while intravenous bolus injection of calcitonin $(1 \mathrm{nmol})$ had no significant effect (Table I).

Cerebroventricular administration of CGRP produced immediate and significant inhibition of duodenal bicarbonate secretion lasting $90 \mathrm{~min}$ (Fig. $2 \mathrm{~A}$ ). Pretreatment of the animals with a vasopressin receptor antagonist did not significantly alter resting duodenal bicarbonate secretion, but significantly attenuated the inhibitory effect of cerebroventricular CGRP (Fig. $2 \mathrm{~A}$ ). At the 30-, 45-, and 60-min time intervals, duodenal bicarbonate secretion was significantly $(P<0.05)$ greater in animals treated with CGRP and the vasopressin antagonist
(Fig. $2 B$ ) than in animals treated with $\mathrm{CGRP}$ and $\mathrm{NaCl}$ as the control (Fig. $2 A$ ).

Pretreatment of the animals with the alpha adrenergic blocking agent, phentolamine, increased resting duodenal bicarbonate secretion from $\sim 12$ to $21 \mu \mathrm{mol} / \mathrm{cm} \cdot \mathrm{h}(\sim 75 \%)$ (Fig. $2 C)$. Phentolamine alone significantly $(P<0.05)$ attenuated the inhibitory effect of CGRP on duodenal bicarbonate secretion (Fig. $2 C$ ), while pretreatment of the animals with phentolamine and the vasopressin receptor antagonist abolished the inhibitory effect of cerebroventricular CGRP (Fig. 2 $D)$. The mean 2-h total bicarbonate outputs $( \pm \mathrm{SE})$ in response to CGRP expressed as a percentage of the $2-h$ total bicarbonate outputs in response to the respective cerebroventricular controls were $\mathrm{NaCl}, 63 \pm 5 \%$; vasopressin receptor antagonist, $81 \pm 6 \%$; phentolamine, $81 \pm 5 \%$; vasopressin receptor antagonist plus phentolamine, $95 \pm 4 \%(P<0.01$ each compared with $\mathrm{NaCl})$.

To assure completeness of vagotomy, duodenal bicarbonate secretion was measured for $1 \mathrm{~h}$ in response to the vagal stimulus 2-deoxy-D-glucose. In sham-operated animals the response was $27.4 \pm 3.7 \mu \mathrm{mol} / \mathrm{cm} \cdot \mathrm{h}$, while in vagotomized animals the response was $12.4 \pm 1 \mu \mathrm{mol} / \mathrm{cm} \cdot \mathrm{h}$ and not significantly different from resting (nonstimulated) bicarbonate secretion, $11.9 \pm 2 \mu \mathrm{mol} / \mathrm{cm} \cdot \mathrm{h}$. Truncal vagotomy and ganglionic blockade with chlorisondamine significantly $(P$ $<0.01$ ) reduced resting duodenal bicarbonate secretion by 35 and $40 \%$, respectively, while noradrenergic blockade with bre-

Table I. Peripheral Effects of CGRP and Calcitonin on Duodenal Bicarbonate Secretion

\begin{tabular}{|c|c|c|c|c|c|c|c|c|c|}
\hline & \multicolumn{9}{|c|}{$\mathrm{HCO}_{3}^{-}$} \\
\hline & $0 \mathrm{~min}$ & $15 \mathrm{~min}$ & $30 \mathrm{~min}$ & $45 \mathrm{~min}$ & $60 \mathrm{~min}$ & $75 \mathrm{~min}$ & $90 \mathrm{~min}$ & $105 \mathrm{~min}$ & $120 \mathrm{~min}$ \\
\hline & & & & & $\mu \mathrm{mol} / \mathrm{cm} \cdot \mathrm{h}$ & & & & \\
\hline Control & $11.5 \pm 0.4$ & $11.5 \pm 0.5$ & $11.9 \pm 0.6$ & $12.0 \pm 0.6$ & $12.1 \pm 1.0$ & $12.1 \pm 1.0$ & $12.6 \pm 0.8$ & $12.4 \pm 0.7$ & $12.2 \pm 0.8$ \\
\hline CGRP & $11.7 \pm 0.6$ & $8.3 \pm 0.8^{*}$ & $10.7 \pm 0.6$ & $10.9 \pm 0.6$ & $11.4 \pm 0.8$ & $11.8 \pm 0.8$ & $11.2 \pm 0.7$ & $11.9 \pm 0.9$ & $11.7 \pm 0.9$ \\
\hline Calcitonin & $11.4 \pm 0.7$ & $11.3 \pm 0.9$ & $11.3 \pm 0.8$ & $11.3 \pm 0.9$ & $11.6 \pm 0.9$ & $11.9 \pm 0.9$ & $11.3 \pm 0.5$ & $10.4 \pm 0.5$ & $10.1 \pm 0.6$ \\
\hline
\end{tabular}

CGRP and calcitonin ( $1 \mathrm{nmol}$ each) were given intravenously at time zero. ${ }^{*} P<0.01$ compared with the corresponding time point of control. 


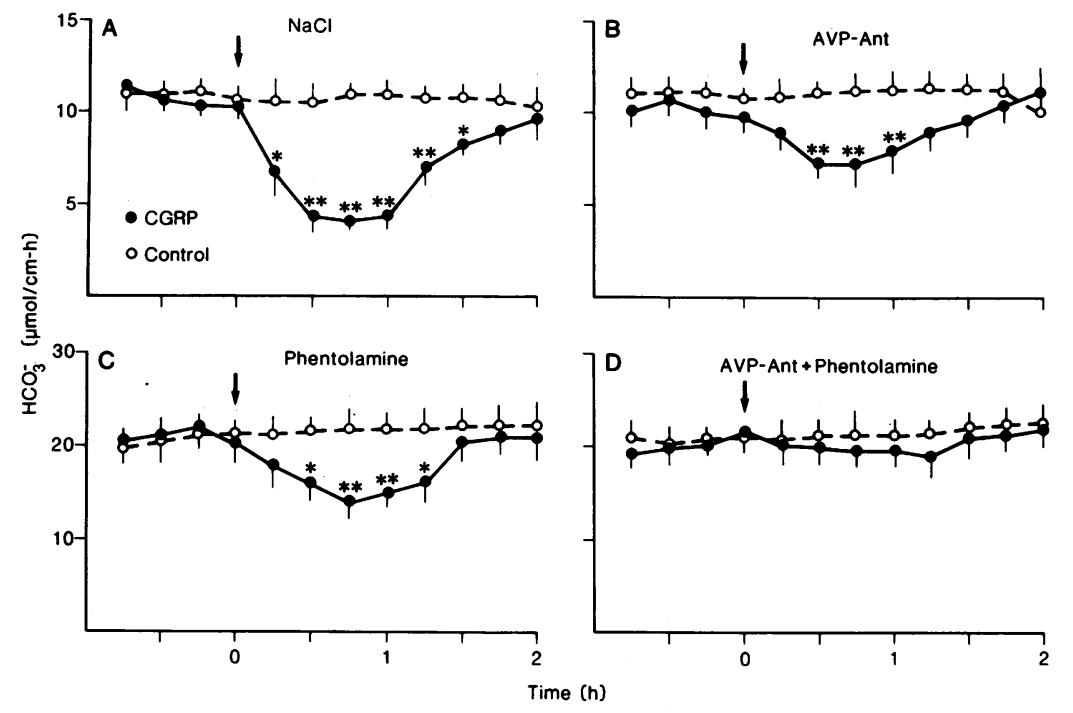

Figure 2. Effects of a vasopressin receptor antagonist $(A V P-A n t)$ and adrenergic receptor blockade (phentolamine) on CGRP-induced inhibition of duodenal bicarbonate secretion. Intravenous infusions with 0.15 $\mathrm{M} \mathrm{NaCl}(A)$, AVP-Ant $(100 \mathrm{nmol} / \mathrm{kg} \cdot \mathrm{h})(B)$, phentolamine $(1 \mu \mathrm{mol} / \mathrm{kg} \cdot \mathrm{h})(C)$, and AVP-Ant + phentolamine $(D)$ were begun $2 \mathrm{~h}$ before cerebroventricular administration of CGRP $(1 \mathrm{nmol})$ or control, indicated by the arrow. Note the differences in the scale of the vertical ordinates between the upper and lower panels. ${ }^{*} P<0.05 ;{ }^{* *} P<0.01$ compared with the corresponding time points of control. tylium did not (Fig. 3). Chlorisondamine completely abolished and bretylium significantly $(P<0.01)$ attenuated inhibition of duodenal bicarbonate secretion induced by cerebroventricular CGRP (Fig. 3, $A$ and $B$ ). In contrast, truncal vagotomy did not attenuate the inhibitory effect of CGRP (Fig. $3 C$ ). The 2-h
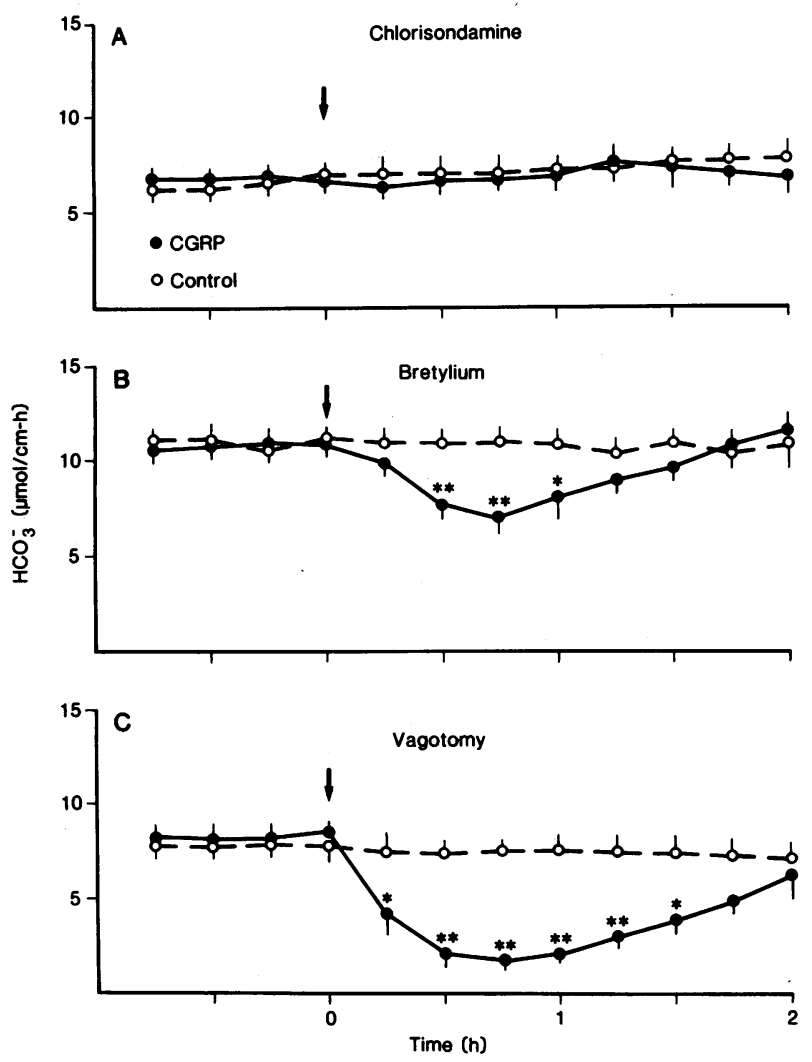

Figure 3. Effects of ganglionic blockade (chlorisondamine), noradrenergic blockade (bretylium), and truncal vagotomy on CGRP-induced inhibition of duodenal bicarbonate secretion. Intravenous infusions with chlorisondamine $(3 \mathrm{mg} / \mathrm{kg} \cdot \mathrm{h})(A)$ and bretylium $(25$ $\mathrm{mg} / \mathrm{kg} \cdot \mathrm{h})(B)$ were begun $2 \mathrm{~h}$ before cerebroventricular administration of CGRP $(1 \mathrm{nmol})$ or control indicated by the arrow. ${ }^{*} P<0.05$; ${ }^{* *} P<0.01$ compared with the corresponding time points of control. total bicarbonate outputs in response to CGRP expressed as a percentage of the total 2-h bicarbonate outputs in response to the respective controls were: bretylium $84 \pm 5 \%$ and vagotomy $46 \pm 3 \%$. These responses were significantly $(P<0.01)$ different from the response produced by CGRP in $\mathrm{NaCl}$-treated ani-

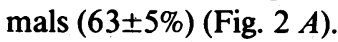

As depicted in Figs. 2 and 3, phentolamine, chlorisondamine, and truncal vagotomy altered the baseline of resting duodenal bicarbonate secretion. To compare the relative effects of these pharmacological and surgical procedures on CGRP-induced inhibition of duodenal bicarbonate secretion, the effects of CGRP were expressed as a percentage of the bicarbonate responses of the appropriate control experiments. The maximal inhibitory effect of CGRP was observed during the third collection interval (30-45 min) after cerebroventricular administration. Therefore, this interval was chosen for comparison. In control animals (no pharmacological pretreatment or surgery) CGRP decreased the bicarbonate response to $37 \pm 5 \%$ (Fig. 4). Vagotomy significantly $(P<0.05)$ enhanced

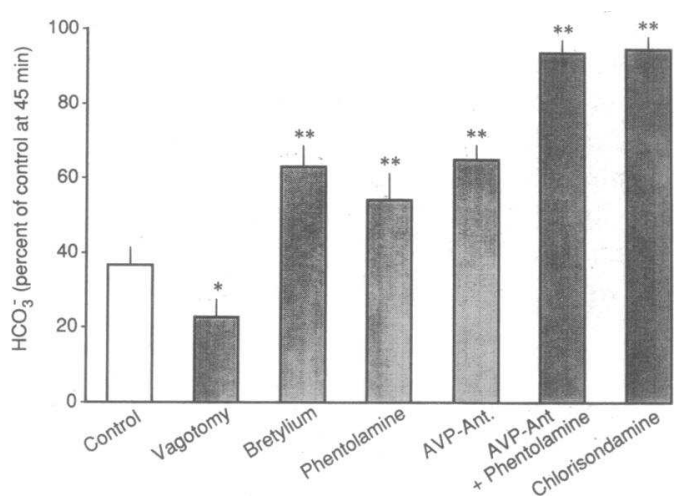

Figure 4. Relative inhibitory effects of cerebroventricular CGRP (1 $\mathrm{nmol}$ ) on duodenal bicarbonate secretion in control experiments $(0.15 \mathrm{M} \mathrm{NaCl}$ infusion) and during autonomic nervous system and vasopressin receptor blockade. CGRP, control, and blocking agents were administered at times indicated in the legends to Figs. 2 and 3. The bicarbonate responses measured at the 30-45-min interval in response to CGRP were expressed as a percentage of the bicarbonate responses measured at the 30-45-min interval in response to the vehicle, sterile water. ${ }^{*} P<0.05 ;{ }^{* *} P<0.01$ compared with control. 
the inhibitory effect of CGRP. Bretylium, phentolamine, and the vasopressin receptor antagonist significantly $(P<0.01)$ reversed the inhibitory effect of CGRP (Fig. 4). Combined treatment with phentolamine and the vasopressin receptor antagonist or ganglionic blockade with chlorisondamine reversed the inhibitory effect of cerebroventricular CGRP on duodenal bicarbonate secretion (Fig. 4).

Hypophysectomy, adrenalectomy, and opiate blockade with naloxone did not significantly alter resting bicarbonate secretion or attenuate the inhibitory effects of CGRP (Table II). Cerebroventricular administration of CGRP ( $1 \mathrm{nmol})$ significantly increased plasma concentrations of vasopressin and NE (Fig. 5) but not of epinephrine (data not shown).

Intraperitoneal administration of increasing doses of vasopressin and NE produced dose-dependent inhibition of duodenal bicarbonate secretion (Fig. 6). Of note, on a molar basis vasopressin appeared to be $\sim 100$ times more potent and effective than NE in inhibiting bicarbonate secretion in vivo. The vasopressin receptor antagonist and the alpha adrenergic antagonist, phentolamine, abolished the effects of exogenous vasopressin and NE on bicarbonate secretion, respectively (Fig. 6). Intraperitoneal administration of vasopressin $(0.25$ $\mathrm{nmol} / \mathrm{kg})$ and $\mathrm{NE}(25 \mathrm{nmol} / \mathrm{kg})$ given concomitantly inhibited duodenal bicarbonate secretion by $63 \pm 4 \%$, while vasopressin and NE given separately inhibited the bicarbonate response by $33 \pm 2$ and $29 \pm 3 \%$, respectively (Fig. 6). Combined treatment with intraperitoneal vasopressin and NE produced inhibition of duodenal bicarbonate secretion that was similar to the response observed after a maximal dose of cerebroventricular CGRP (5 nmol/kg) (Fig. 6). Pretreatment of the animals with the vasopressin receptor antagonist and phentolamine completely reversed the inhibitory effect produced by intraperitoneal administration of vasopressin and NE (Fig. 6).

To evaluate if the exogenously administered doses of vasopressin and NE produced similar plasma concentrations that were observed after cerebroventricular administration of CGRP, the highest doses that were used in the bioassay were given intraperitoneally. Vasopressin $(0.5 \mathrm{nmol} / \mathrm{kg})$ and $\mathrm{NE}(50$ $\mathrm{nmol} / \mathrm{kg})$ significantly $(P<0.05)$ increased plasma vasopressin and NE concentrations (Table III). While vasopressin administration produced plasma vasopressin concentrations that were similar to those observed in response to cerebroventricular administration of CGRP (at $30 \mathrm{~min}$ ), NE administration produced plasma NE concentrations that were significantly $(P$

Table II. Inhibition of Duodenal Bicarbonate Secretion by CGRP: Role of the Pituitary, Adrenals, and Opiate Receptors

\begin{tabular}{|c|c|c|}
\hline & \multicolumn{2}{|c|}{$\mathrm{HCO}_{3}^{-}$} \\
\hline & Control & CGRP \\
\hline & \multicolumn{2}{|c|}{$\mu \mathrm{mol} / \mathrm{cm} \cdot \mathrm{h}$} \\
\hline $\mathrm{NaCl}$ & $11.9 \pm 0.8$ & $4.8 \pm 0.7^{*}$ \\
\hline Hypophysectomy & $10.1 \pm 0.5$ & $4.3 \pm 0.5^{*}$ \\
\hline Adrenalectomy & $10.5 \pm 0.6$ & $5.1 \pm 0.9^{*}$ \\
\hline Naloxone & $10.5 \pm 0.9$ & $6.1 \pm 1.1^{*}$ \\
\hline
\end{tabular}

Bicarbonate secretion was measured $30-45 \mathrm{~min}$ after cerebroventricular administration of CGRP ( $1 \mathrm{nmol}$ ) or control. Naloxone infusion $(1 \mathrm{mg} / \mathrm{kg} \cdot \mathrm{h})$ was begun $2 \mathrm{~h}$ before cerebroventricular injection. ${ }^{*} P$ $<0.01$ compared with control.

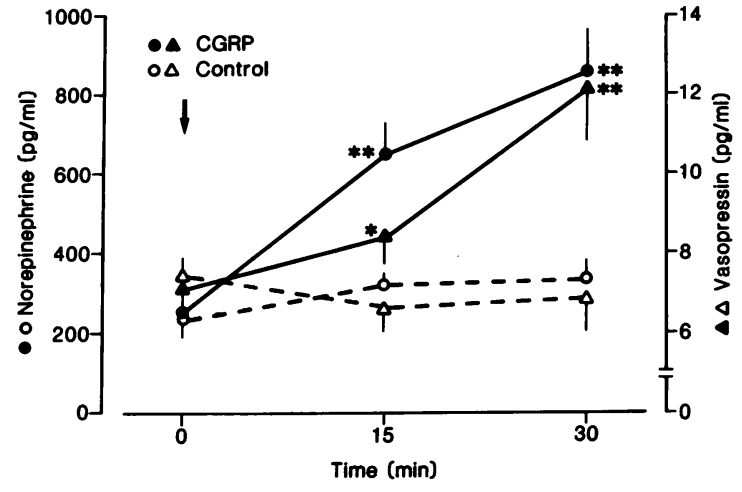

Figure 5. Effects of cerebroventricular administration of CGRP (1 $\mathrm{nmol}$ ) and control (vehicle) on plasma concentrations of $\mathrm{NE}$ and vasopressin. ${ }^{*} P<0.05 ;{ }^{* *} P<0.0 .1$ compared with the corresponding time points of control.

$<0.05$ ) less than those observed after cerebroventricular administration of CGRP (Table III, Fig. 5).

\section{Discussion}

Like most gut secretory processes, duodenal mucosal bicarbonate secretion is under the control of the autonomic nervous system. Stimulation of parasympathetic (vagal) efferents increases, while stimulation of sympathetic (splanchnic) efferents decreases duodenal bicarbonate secretion in a number of species $(6,7,26,27)$. The central nervous system transmitters that promote these responses are largely unknown. We have recently provided evidence that thyrotropin-releasing hormone is a candidate neurotransmitter that stimulates duodenal bicarbonate secretion by increasing vagal outflow (9). To the best of our knowledge, CGRP is the only oligopeptide to date that acts centrally to inhibit duodenal bicarbonate secretion (10). This study examined the central nervous system effects of CGRP on proximal duodenal bicarbonate secretion in a newly developed animal model that permits measurement of duodenal bicarbonate secretion in freely moving animals (8).

Intravenous administration of the gastrointestinal peptides neurotensin and VIP and intraluminal perfusion of the duodenum with a $\mathrm{PGE}_{1}$ analogue and $\mathrm{HCl}$ increased bicarbonate secretion, extending previous observations in restrained or anesthetized rats $(2,28-30)$, conscious dogs (4), and humans (1). Intraluminal PGs and circulating neurotensin and VIP stimulate duodenal bicarbonate secretion by distinct mechanisms $(4,28-30)$ and intraluminal $\mathrm{HCl}$ stimulates bicarbonate secretion via a PG- and VIP-dependent mechanism $(2,30)$. Therefore, the peripheral transmitters (i.e., NE and vasopressin) released in response to cerebroventricular CGRP probably interfere with each of these mechanisms.

Cerebroventricular administration of CGRP produced dose-dependent and long-lasting inhibition of resting (basal) bicarbonate secretion, while intravenous administration of CGRP exhibited a transient inhibitory effect. The peripheral effect of CGRP on bicarbonate secretion may be secondary to the peptide's pronounced peripheral hypotensive effect since the marked decrease in mean arterial pressure in an earlier study (12) preceded the transient decrease in bicarbonate secretion observed in this study. Differences in the time course of 


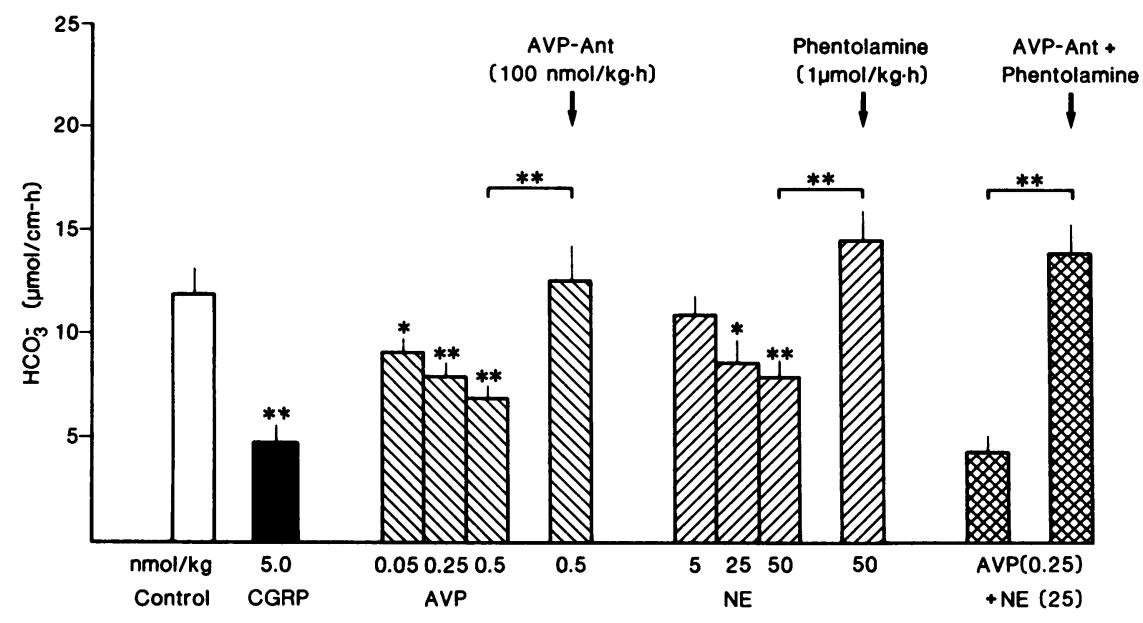

Figure 6. Effects of intraperitoneal administration of vasopressin $(A V P)$ and NE on duodenal bicarbonate secretion. Bicarbonate secretion was measured 30-45 min after injection of AVP and NE. The vasopressin receptor antagonist $(A V P-A n t)$ and phentolamine infusions were commenced $2 \mathrm{~h}$ before administration of AVP and NE. For comparison, CGRP $(5 \mathrm{nmol} / \mathrm{kg})$ was given cerebroventricularly. ${ }^{*} P$ $<0.05 ;{ }^{* *} P<0.01$ compared with control unless indicated otherwise. Intraperitoneal AVP + NE produced a bicarbonate response that was similar to the bicarbonate response produced by a maximal dose of CGRP. peptide action after central and peripheral administration also suggest differences in site of action; i.e., cerebroventricular CGRP acts within the central nervous system, while intravenous CGRP acts at a peripheral, as yet unidentified site (15).

While the central nervous system effects of CGRP and calcitonin on gastric acid secretion and gastrointestinal transit are similar $(16,17,19,31)$, unlike CGRP, calcitonin does not inhibit duodenal bicarbonate secretion. This observation suggests that rat calcitonin is not a ligand for the cerebral CGRP receptor $(32,33)$ involved in mediating the peptide's effect on duodenal bicarbonate secretion. Distinct receptors for CGRP and calcitonin have also been implicated in mediating the inhibitory effects of these two peptides on gastric acid secretion and gastrointestinal transit $(19,31)$. However, the precise cerebral site of action of CGRP to inhibit duodenal bicarbonate secretion remains to be elucidated.

To determine the pathways that mediate the inhibitory effects of cerebroventricular CGRP surgical and pharmacological procedures were used. Ganglionic blockade and truncal vagotomy significantly decreased resting bicarbonate secretion, suggesting that parasympathetic efferents not only stimulate $(6,26,27)$ but also exert a tonic effect on proximal duodenal bicarbonate secretion. In contrast, blockade of vasopressin and opiate receptors using specific antagonists, and preventing the release of NE from adrenergic nerve endings with bretylium, as well as adrenalectomy and hypophysectomy, did not significantly alter resting duodenal bicarbonate secretion, suggesting that none of these pathways is involved in

Table III. Plasma Vasopressin and NE Concentrations

\begin{tabular}{lccccc}
\hline & \multicolumn{2}{c}{ Vasopressin } & & \multicolumn{2}{c}{$\mathrm{NE}$} \\
\cline { 2 - 3 } \cline { 5 - 6 } & $0 \mathrm{~min}$ & $30 \mathrm{~min}$ & & $0 \mathrm{~min}$ & $30 \mathrm{~min}$ \\
\hline & \multicolumn{3}{c}{$p g / \mathrm{ml}$} \\
$\mathrm{AVP}+\mathrm{NE}$ & $8.0 \pm 0.7$ & $14.3 \pm 4.6^{*}$ & $248 \pm 19$ & $302 \pm 29^{*}$ \\
Control & $7.0 \pm 1.9$ & $6.3 \pm 0.6$ & & $197 \pm 12$ & $233 \pm 19$ \\
\hline
\end{tabular}

Effects of concomitant intraperitoneal administration of vasopressin (AVP; $0.5 \mathrm{nmol} / \mathrm{kg})$ and $\mathrm{NE}(50 \mathrm{nmol} / \mathrm{kg})$ or control $(0.15 \mathrm{M} \mathrm{NaCl})$ on plasma vasopressin and $\mathrm{NE}$ concentrations. Agents were given at $0 \mathrm{~min}$.

* $P<0.05$ compared with the corresponding control. the tonic control of duodenal bicarbonate secretion $(8,9)$. Of note, the nonselective alpha adrenoceptor antagonist phentolamine significantly increased resting bicarbonate secretion in this and in a previous study by an as yet unidentified mechanism (34). It is possible that phentolamine stimulates bicarbonate secretion either by acting directly on receptors of the mucosal cells or by vasodilation and increased splanchnic blood flow (35).

Most importantly, the results of this study demonstrate that CGRP given cerebroventricularly increases plasma concentrations of $\mathrm{NE}$ (12) and vasopressin, and that the release of both NE and vasopressin coincides with the inhibitory effect of CGRP on duodenal bicarbonate secretion. Phentolamine and the vasopressin antagonist reversed CGRP-induced inhibition of bicarbonate secretion by $\sim 50 \%$ each, and both agents together abolished the inhibitory effect of CGRP. Furthermore, exogenous administration of vasopressin and NE resulting in plasma concentrations that were similar to or less than those observed after central administration of CGRP produced dose-dependent inhibition of bicarbonate secretion. Their combined inhibitory effects were additive and abolished by the vasopressin and alpha adrenergic receptor antagonists, respectively. These observations indicate that cerebroventricular CGRP inhibits duodenal bicarbonate secretion by release of vasopressin and NE, which exert their peripheral inhibitory effects on bicarbonate secretion via specific vasopressin and alpha adrenergic receptors, respectively. The results also imply synergism between vasopressin and NE as reflected by their additive inhibitory effects. Further studies using isolated organ or cell preparations are needed to determine the precise localization of vasopressin and noradrenergic receptors and their cellular interactions that are involved in regulating duodenal bicarbonate secretion.

In contrast to our findings in awake, nonrestrained rats, NE did not significantly alter duodenal bicarbonate secretion in anesthetized rats, but attenuated the stimulatory effect of phentolamine (34). The experimental design (i.e., state of anesthesia and in vitro back-titration in this study versus continuous pH stat titration and $\sim 20$ times lower doses of NE used in our experiments) may account for these different observations (34). The present findings demonstrating that noradrenergic blockade with bretylium attenuates inhibition of bicarbonate secretion produced by CGRP-induced increase in sympathetic noradrenergic outflow concurs with previous findings 
that noradrenergic blockade with guanethidine abolished the inhibitory effect of splanchnic nerve stimulation (7).

The observation that ganglionic blockade with chlorisondamine abolished the inhibitory effect of CGRP indicates that autonomic efferents are involved. This finding also suggests that ganglionic blockade affects both the noradrenergic and vasopressin-sensitive pathways that mediate the inhibitory effects of CGRP. Of interest, hypophysectomy did not prevent the inhibitory effects of CGRP on bicarbonate secretion, suggesting that nonpituitary vasopressin is released by cerebroventricular administration of CGRP. A vasopressin-like peptide has been identified in the mammalian sympathetic nervous system, including in the principal noradrenergic neurones of ganglia and in nerve fibers innervating peripheral tissues (36). These findings support the contention that CGRP may corelease NE and vasopressin from sympathetic neuronal fibers rather than from the adrenal glands, since adrenalectomy did not alter the duodenal inhibitory effect of CGRP. However, the precise site of CGRP-induced vasopressin release remains to be determined.

Inhibition of gastric acid secretion and gastrointestinal transit induced by cerebroventricular administration of CGRP appears to be mediated by parasympathetic (vagal) efferent fibers and not by noradrenergic efferents $(13,17,19)$. In this study vagotomy did not attenuate the inhibitory effect of CGRP on duodenal bicarbonate secretion. In addition, loss of vagal control further accentuated the inhibitory effect of CGRP, suggesting that removal of vagal transmitters facilitated inhibition of bicarbonate secretion induced by increased noradrenergic drive. Conversely, cerebroventricular corticotropin-releasing factor inhibits gastric acid secretion predominantly by increasing sympathetic outflow $(20,37)$, but modulates intestinal transit by altering parasympathetic outflow (38).

The physiological importance of CGRP increasing sympathetic outflow and thereby regulating duodenal bicarbonate secretion is unknown. Hemorrhagic shock decreases duodenal bicarbonate secretion and produces mucosal damage (39). Furthermore, hemorrhage-induced hyposecretion of duodenal bicarbonate is mediated by activation of sympathetic nerves (40). Therefore, it is tempting to speculate that under these conditions CGRP may serve as an endogenous central nervous system mediator.

In summary, the results of this study indicate that CGRP acts within the central nervous system to inhibit resting and stimulated proximal duodenal bicarbonate secretion in awake, nonrestrained rats. CGRP exerts this action by enhancing sympathetic, noradrenergic outflow that results in release of $\mathrm{NE}$ and possibly nonpituitary vasopressin released from adrenergic nerve endings. NE and vasopressin inhibit duodenal bicarbonate secretion via specific noradrenergic and vasopressin receptors, respectively, and their inhibitory effects are additive.

\section{Acknowledgments}

We thank E. Friemel, K. Feutlinske, and K. Karber-Moore for expert technical assistance, Dr. J. E. Rivier for supply of the peptides, and Dr. J. I. Isenberg for critical reading of the manuscript.

This work was supported by the Deutsche Forschungsgemeinschaft grant Le470/2-1, by the Hamburgische Wissenschaftliche Stiftung, and by National Institutes of Health grant HL-37716.

\section{References}

1. Isenberg, J. I., D. L. Hogan, M. A. Koss, and J. A. Selling. 1986. Human duodenal mucosal bicarbonate secretion: evidence for basal secretion and stimulation by hydrochloric acid and a synthetic prostaglandin $\mathrm{E}_{1}$ analogue. Gastroenterology. 91:370-378.

2. Isenberg, J. I., B. Smedfors, and C. Johansson. 1985. Effect of graded doses of intraluminal $\mathrm{H}^{+}$, prostaglandin $\mathrm{E}_{2}$, and inhibition of endogenous prostaglandin synthesis on proximal duodenal bicarbonate secretion in unanesthetized rat. Gastroenterology. 88:303-307.

3. Flemström, G., A. Garner, O. Nylander, B. C. Hurst, and J. R. Heylings. 1982. Surface epithelial $\mathrm{HCO}_{3}^{-}$transport by mammalian duodenum in vivo. Am. J. Physiol. 243:G348-G358.

4. Konturek, J. S., J. Bilska, J. Tasler, and J. Laskiewicz. 1985. Gut hormones in stimulation of gastroduodenal alkaline secretion in conscious dogs. Am. J. Physiol. 248:G687-G691.

5. Isenberg, J. I., J. A. Selling, D. L. Hogan, and M. A. Koss. 1987. Impaired proximal duodenal mucosal bicarbonate secretion in patients with duodenal ulcer. $N$. Engl. J. Med. 316:374-379.

6. Nylander, O., G. Flemström, D. Delbro, and L. Fändriks. 1987. Vagal influence on gastroduodenal $\mathrm{HCO}_{3}^{-}$secretion in the cat in vivo. Am. J. Physiol. 252:G522-G528.

7. Jönson, C., and L. Fändriks. 1988. Splanchnic nerve stimulation inhibits duodenal $\mathrm{HCO}_{3}^{-}$secretion in the rat. Am. J. Physiol. 255:G709-G712.

8. Lenz, H. J. 1989. Regulation of duodenal bicarbonate secretion during stress by corticotropin-releasing factor and $\beta$-endorphin. Proc. Natl. Acad. Sci. USA. 86:1417-1420.

9. Lenz, H. J., W. W. Vale, and J. E. Rivier. 1989. TRH-induced vagal stimulation of duodenal $\mathrm{HCO}_{3}^{-}$mediated by VIP and muscarinic pathways. Am. J. Physiol. 256:G677-G682.

10. Lenz, H. J., I. Forquignon, G. Drüge, and H. Greten. 1989. Effects of neuropeptides on gastric acid and duodenal bicarbonate secretions in freely moving rats. Regul. Pept. 24:293-300.

11. Rosenfeld, M. G., J.-J. Mermod, S. G. Amara, L. W. Swanson, P. E. Sawchenko, J. Rivier, W. W. Vale, and R. M. Evans. 1983. Production of a novel neuropeptide encoded by the calcitonin gene via tissue-specific gene expression. Nature (Lond.). 304:129-135.

12. Fisher, L. A., D. O. Kikkawa, J. E. Rivier, S. G. Amara, R. M. Evans, M. G. Rosenfeld, W. W. Vale, and M. R. Brown. 1983. Stimulation of noradrenergic sympathetic outflow by calcitonin gene-related peptide. Nature (Lond.). 305:534-536.

13. Tache, Y., M. Lauffenberger, and Y. Goto. 1984. Inhibition of gastric acid secretion by cerebroventricular injection of calcitonin gene-related peptide. Life Sci. 35:871-878.

14. Hughes, J. J., A. S. Levine, J. E. Morley, B. A. Gosnell, and S. E. Silvis. 1984. Peptides (NY). 5:258-261.

15. Lenz, H. J., M. T. Mortrud, J. E. Rivier, W. W. Vale, and M. R. Brown. 1984. Calcitonin gene-related peptide acts within the brain to inhibit gastric acid secretion. Regul. Pept. 9:271-277.

16. Lenz, H. J., J. E. Rivier, and M. R. Brown. 1985. Biological actions of human and rat calcitonin and calcitonin gene-related peptide. Regul. Pept. 12:81-89.

17. Lenz, H. J., M. T. Mortrud, J. E. Rivier, and M. R. Brown. 1985. Central nervous system actions of calcitonin gene-related peptide on gastric acid secretion in the rat. Gastroenterology. 88:539-544.

18. Lenz, H. J., S. E. Hester, R. P. Saik, and M. R. Brown. 1986. CNS actions of calcitonin gene-related peptide on gastric acid secretion in conscious dogs. Am. J. Physiol. 250:G742-G748.

19. Lenz, H. J. 1988. Calcitonin and CGRP inhibit gastrointestinal transit via distinct neuronal pathways. Am. J. Physiol. 254:G920G924.

20. Drüge, G., A. Raedler, H. Greten, and H. J. Lenz. 1989. Pathways mediating CRF-induced inhibition of gastric acid secretion in rats. Am. J. Physiol. 256:G214-G219.

21. Brown, M. R., and L. A. Fisher. 1983. Central nervous system effects of corticotropin-releasing factor in the dog. Brain Res. 280:7579. 
22. Peuler, J. D., and G. A. Johnson. 1977. Simultaneous single isotope radioenzymatic assay of plasma norepinephrine, epinephrine, and dopamine. Life Sci. 21:625-636.

23. Fernstrom J. D., L. A. Fisher, B. M. Cusack, and M. A. Gillis. 1980. Radioimmunologic detection and Measurement of nonapeptides in the pineal gland. Endocrinology. 106:243-251.

24. Fisher, L. A., A. J. Schlosberg, and J. D. Fernstrom. 1981. The pineal does not concentrate arginine vasotocin from biological fluids in vivo. Endocr. Res. Commun. 8:135-144.

25. Zar, J. H. 1974. Biostatistical Analysis. Prentice-Hall, Englewood Cliffs, NJ. 620 pp.

26. Konturek, S. J., P. Thor, J. Bilski, J. Tasler, and M. Cieszkowski. 1987. Cephalic phase of gastroduodenal alkaline secretion Am. J. Physiol. 252:G742-G747.

27. Ballesteros, M. A., D. L. Hogan, M. A. Koss, H. S. Chen, and J. I. Isenberg. 1988. Vagal stimulation of human duodenal bicarbonate secretion (DBS) acts by non-cholinergic mechanisms. Gastroenterology. 94:A20. (Abstr.)

28. Isenberg, J. I., B. Wallin, C. Johansson, B. Smedfors, V. Mutt, K. Tatemoto, and S. Emas. 1984. Secretin, VIP, and PHI stimulate rat proximal duodenal surface epithelial bicarbonate secretion in vivo. Regul. Pept. 8:315-320.

29. Flemström, G., G. Jedstedt, and O. Nylander. 1985. Effects of some opiates and vasoactive intestinal peptide (VIP) on duodenal surface epithelial bicarbonate secretion in the rat. Scand. J. Gastroenterol. Suppl. 110:49-53.

30. Algazi, M. C., H. S. Chen, M. A. Koss, D. L. Hogan, J. Steinbach, S. J. Pandol, and J. I. Isenberg. 1989. Effect of VIP antagonist on VIP, PGE and acid-stimulated duodenal bicarbonate secretion. Am. J. Physiol. 256:G833-G836.

31. Lenz, H. J., and M. R. Brown. 1987. Intracerebroventricular administration of human calcitonin and human calcitonin gene-re- lated peptide inhibits meal-stimulated gastric acid secretion in the dog. Dig. Dis. Sci. 32:409-416.

32. Seifert, H., J. Chesnut, E. DeSouza, J. Rivier, and W. Vale. 1985. Binding sites for calcitonin gene-related peptid in distinct areas of rat brain. Brain Res. 346:195-198.

33. Henke, H., F. A. Tschopp, and J. A. Fisher. 1985. Distinct binding sites for calcitonin gene-related peptide and salmon calcitonin in rat central nervous system. Brain Res. 360:165-171.

34. Nylander, O., and G. Flemström. 1986. Effects of alpha-adrenoceptor agonists and antagonists on duodenal surface epithelial $\mathrm{HCO}_{3}^{-}$secretion in the rat in vivo. Acta Physiol. Scand. 126:433-441.

35. Weiner, N. 1980. Drugs that inhibit adrenergic nerves and block adrenergic receptors. In The Pharmacological Basis of Therapeutics. A. G. Gilman, L. S. Goodman, and A. Gilman, editors. Macmillan Publishing Co., New York. 176-210.

36. Hanley, M. R., H. P. Benton, S. L. Lightman, K. Todd, E. A. Bone, P. Fretten, S. Palmer, C. J. Kirk, and R. H. Michell. 1984. A vasopressin-like peptide in the mammalian sympathetic nervous system. Nature (Lond.). 309:258-261.

37. Lenz, H. J., S. E. Hester, and M. R. Brown. 1985. Corticotropin-releasing factor. Mechanisms to inhibit gastric acid secretion in conscious dogs. J. Clin. Invest. 75:889-895.

38. Lenz, H. J., M. Burlage, A. Raedler, and H. Greten. 1988. Central nervous system effects of corticotropin-releasing factor on gastrointestinal transit in the rat. Gastroenterology. 94:103-108.

39. Takeuchi, K., Y. Nobuhara, H. Tanaka, H. Nishiwaki, and S. Okabe. 1988. Effects of hemorrhagic shock on alkaline secretion and mucosal tolerance to acid in rat duodenum: a comparative study with indomethacin. Dig. Dis. Sci. 33:1409-1417.

40. Jönson, C., and L. Fändriks. 1987. Bleeding inhibits vagally induced duodenal $\mathrm{HCO}_{3}^{-}$secretion via activation of the splanchnic nerves in anesthetized rats. Acta Physiol. Scand. 130:259-264. 